\title{
Sequence networks to the calculation of two-simultaneous faults at the same location
}

\author{
Ailson P. Moura ${ }^{a, b, *}$, J.A. Peças Lopes ${ }^{c}$, Adriano A.F. de Moura ${ }^{d}$ \\ ${ }^{a}$ Department of Electrical Engineering, Federal University of Ceara, Pici Campus, Brazil \\ ${ }^{\mathrm{b}}$ CAPES Foundation, Brazil \\ ' Faculty of Electrical and Computer Engineering, University of Porto, Instituto de Engenharia de Sistemas e Computadores do Porto (INESCPorto), $4200-465$ Porto, Portugal

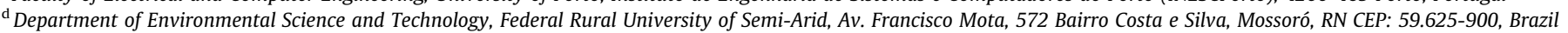

\section{A R T I C L E I N F O}

\section{Article history:}

Received 6 December 2013

Received in revised form 21 January 2015

Accepted 31 January 2015

Available online 18 February 2015

\section{Keywords:}

Fault

Power system

Sequence networks

Symmetrical components

\begin{abstract}
A B S T R A C T
The system of symmetrical components (012-system) can be used to simulate symmetrical and asymmetrical operation of power systems. However, the classical literature of Power Systems Analysis does not present one equivalent circuit in 012-system to two-simultaneous faults where there are a singleline-to-ground fault and a bolted line-to-line fault. This paper presents the equations and the new equivalent circuit mentioned. In addition, we present a comparison of results between the proposed approach and the output of the commercial software ANAFAS, which validates the methodology. We find evidence that the new equivalent circuit developed can substitute the equivalent circuits used to calculate a single line-to-ground fault and a bolted line-to-line fault.
\end{abstract}

(c) 2015 Elsevier Ltd. All rights reserved.

\section{Introduction}

The system of symmetrical components can be used for the analysis of symmetrical and asymmetrical operation of power systems. Faults in general and in particular short-circuit currents are the most severe operating conditions in power systems. Hence, each of the different faults, e.g., single-phase-to-ground, threephase, etc., can be represented by an equivalent circuit diagram in the ABC-system (system of phase components) and by this in the 012-system (system of symmetrical components) as well.

One of the most difficult problems in the solution of faulted networks is that involving two or more faults which occur simultaneously [1].

On the other hand, the need to improve service availability has increased the complexity of distribution network topology. Disconnected switches allow transferring loads to alternate sources under emergency conditions. Limitations on the rights of way make it necessary to use multicircuit overhead lines or single-circuit lines that run close to each other. As a result, simultaneous faults involving more than one circuit are becoming quite common. Typical causes which forces more than one fault at a single location include [2]:

* Corresponding author at: Department of Electrical Engineering, Federal University of Ceara, Pici Campus, Brazil.

E-mail addresses: ailson@ufc.br (A.P. Moura), jpl@fe.up.pt (J.A.P. Lopes), adrianoaron@ieee.org (A.A.F. de Moura).
- Multicircuit lines or lines sharing the same right of way.

- Switching operations.

- A stroke of lightning (thunderstorms).

- A man-caused accident.

The classical books of Power Systems Analysis [1,3,4] present the following equivalent circuits for two-simultaneous faults at the same location: Bolted three-phase (two-simultaneous bolted line-to-line fault), three-phase to ground (two-simultaneous lineto-line-to-ground fault) and line-to-line-to-ground (two-simultaneous line-to-ground fault). However, one common drawback of the Power Systems Analysis literature [1,3-5] is not presenting a procedure to derive an equivalent circuit to handle two-simultaneous faults of the type: single-line-to-ground fault and a bolted line-to-line fault (SLG-BLL-F). Furthermore, several other past and recent publications do not fill this gap as the references [6-15].

In Power Engineering, the specific topic about fault analysis receives much attention, as it is deeply important for the electric power industry. This importance is justified by the fact that fault analysis precedes power system protection studies. Take for example: when simultaneous faults occur on the transmission line, they have an effect on the operation of distance relays installed in the system. During faults, it is mandatory for the protection system to operate precisely. Therefore, if the simultaneous faults could be analyzed, it would be very useful [16]. Thus, it is important that also simultaneous SLG-BLL-F is studied. 
This paper provides the equations and a new equivalent circuit in the 012-system to a simultaneous SLG-BLL-F at the same location of the three-phase power system.

The paper is organized as follows: Firstly, a complete demonstration of the proposed equivalent circuit is presented. Secondly the equivalent circuit is validated. Numerical examples show step-by-step how to calculate a simultaneous SLG-BLL-F. Final conclusions and references are contained in this paper as well.

\section{Equivalent circuit diagram in the 012-system}

Whichever fault in the three-phase a.c. system has to be described by three independent conditions for the voltages, currents or combinations of both. Since any of the three phases can be arbitrarily labeled phase a, we do not consider single line-to-ground faults on other phases. The fault equations in the $\mathrm{ABC}$-system are presented in the case of two-simultaneous faults where there are simultaneous SLG-BLL-F as follows.

$V_{a}=z_{f} I_{a} ; \quad I_{b}=-I_{c} ; \quad V_{b}=V_{c}$

where single-line-to-grounded fault impedance (SLGI) is $z_{f}$.

The transformation into the system of symmetrical components is carried out using the transformation matrices by Eqs. (2) and (3).

$\left[\begin{array}{l}V_{a} \\ V_{b} \\ V_{c}\end{array}\right]=\left[\begin{array}{ccc}1 & 1 & 1 \\ 1 & \vec{a}^{2} & \vec{a} \\ 1 & \vec{a} & \vec{a}^{2}\end{array}\right]\left[\begin{array}{l}V_{a_{0}} \\ V_{a_{1}} \\ V_{a_{2}}\end{array}\right]$

$\left[\begin{array}{l}V_{a_{0}} \\ V_{a_{1}} \\ V_{a_{2}}\end{array}\right]=\frac{1}{3}\left[\begin{array}{ccc}1 & 1 & 1 \\ 1 & \vec{a} & \vec{a}^{2} \\ 1 & \vec{a}^{2} & \vec{a}\end{array}\right]\left[\begin{array}{l}V_{a} \\ V_{b} \\ V_{c}\end{array}\right]$

where $\vec{a}=1<120^{\circ}$

The fault equations for the currents in the system of symmetrical components are

$\left[\begin{array}{l}I_{a_{0}} \\ I_{a_{1}} \\ I_{a_{2}}\end{array}\right]=\frac{1}{3}\left[\begin{array}{ccc}1 & 1 & 1 \\ 1 & \vec{a} & \vec{a}^{2} \\ 1 & \vec{a}^{2} & \vec{a}\end{array}\right]\left[\begin{array}{c}I_{a} \\ -I_{c} \\ I_{c}\end{array}\right]$

Therefore,

$I_{a}=3 I_{a_{0}}$

$I_{a_{1}}=-I_{a_{2}}+2 I_{a_{0}}$

and for the voltages

$\left[\begin{array}{l}V_{a_{0}} \\ V_{a_{1}} \\ V_{a_{2}}\end{array}\right]=\frac{1}{3}\left[\begin{array}{ccc}1 & 1 & 1 \\ 1 & \vec{a} & \vec{a}^{2} \\ 1 & \vec{a}^{2} & \vec{a}\end{array}\right]\left[\begin{array}{l}V_{a} \\ V_{b} \\ V_{b}\end{array}\right]$

Therefore,

$V_{a_{1}}=V_{a_{2}}$

The fault conditions as per Eqs. 4(a)-(4e) can only be realized by a series-parallel connection of the positive-, negative- and zero-sequence component. The equivalent circuit diagram in the system of symmetrical components is outlined in Fig. 1. The positive-, negative- and zero-sequence component are represented by impedances $Z_{1}, Z_{2}$ and $Z_{0}$, with $Z_{0}=z_{0}+3 z_{f}$. Where $z_{0}$ is the zero sequence impedance network.

The currents and voltages of the system of symmetrical components are then calculated as

$I_{a_{1}}=\frac{E_{1}\left(4 Z_{2}+Z_{0}\right)}{D} ; \quad I_{a_{2}}=-\frac{E_{1} Z_{0}}{D} ; \quad I_{a_{0}}=\frac{2 E_{1} Z_{2}}{D}$

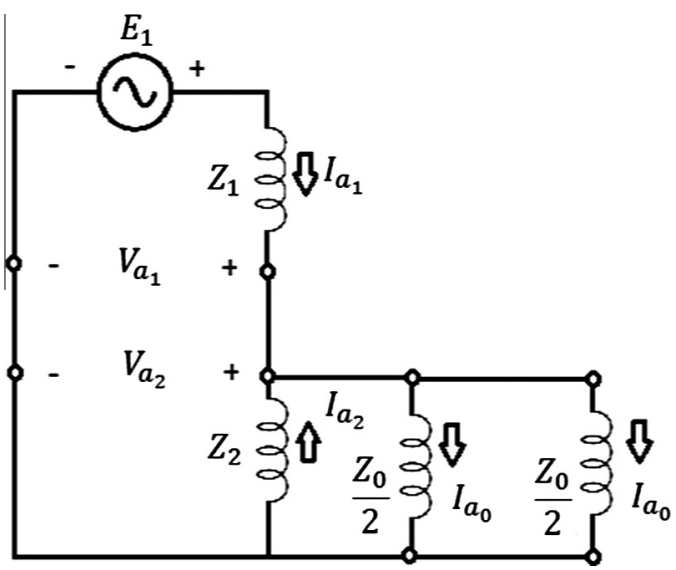

Fig. 1. Equivalent circuit diagram in the 012-system to simultaneous SLG-BLL-F.

$V_{a_{1}}=E_{1}-Z_{1} I_{a_{1}} ; \quad V_{a_{2}}=-Z_{2} I_{a_{2}} ; \quad V_{a_{0}}=-2 V_{a_{1}}+3 z_{f} I_{a_{0}}$

where

$$
D=Z_{2} Z_{0}+Z 1(4 Z 2+Z 0)
$$

\section{Validating the circuit developed}

Fault currents calculation is a key factor in determining the tap settings of protection relays for many practical applications.

The commercial software Simultaneous Fault Analysis (ANAFAS), developed by the Electric Energy Researches Center (CEPEL) - Brazil, was used just for verification of the fault currents and voltages calculation.

Consider the modified Example 3.1 of the reference [1]. The Thevenin voltage at bus $C$ is $E_{1}=1.0(\mathrm{pu})$. The simple power system shown in Fig. 2, consists of a generator, transformer, transmission line, load transformer, and load. Consider simultaneous SLG-BLL-F at bus $C$ with a SLGI of 4 ohms.

The following data concerning the system is known: Generator: 25 MVA, $10 \mathrm{kV}, x=0.125 \mathrm{pu}$, connected Y-grounded. T1: $30 \mathrm{MVA}$, $10-20 \mathrm{kV}, x=0.105$, connected $\Delta-Y$-grounded. Line: $Z=2+\mathrm{j} 4$ ohm. T2: 20 MVA, $5-20 \mathrm{kV}, x=0.05$, connected $Y-\Delta$. Load: static (constant $z$ ) load of $10+\mathrm{j} 5 \mathrm{MVA}$ at $5 \mathrm{kV}$.

\section{Solution}

According to reference [1], the impedances (pu) calculated are: $Z_{1}=0.1287+0.3059 j ; Z_{2}=Z_{1} ; z_{f}=0.2 ; Z_{0}=0.1+0.27 j+3 z_{f}=$ $0.7+0.27 j$.

Now, we may synthesize phase currents and phase voltages both in pu. We calculate the phase currents and the phase voltages to the equivalent circuit using Eqs. (5a), (5b) and (2).

Table 1 shows the results obtained to simultaneous SLG-BLL-F at bus $\mathrm{C}$.

The results from equivalent circuit and the results from ANAFAS can be seen to be much closer. Therefore, the equivalent circuit proposed can be considered as validated.

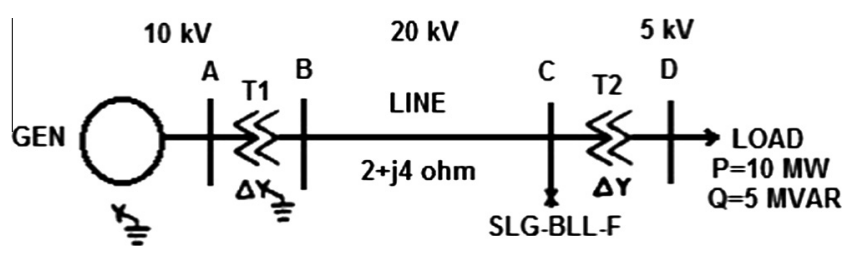

Fig. 2. Power system. 
Table 1

Two-simultaneous fault results.

\begin{tabular}{|c|c|c|}
\hline \multicolumn{2}{|l|}{ ANAFAS } & \multirow{2}{*}{$\begin{array}{l}\text { Equivalent circuit } \\
\text { SLG-BLL-F }\end{array}$} \\
\hline $\mathrm{I} / \mathrm{V}(\mathrm{pu})$ & SLG-BLL-F & \\
\hline$I_{a}$ & $2.305 \angle-42.6^{\circ}$ & $2.3048 \angle-42.6462^{\circ}$ \\
\hline$I_{b}$ & $2.610 \angle-157.2^{\circ}$ & $2.6095 \angle-157.1823^{\circ}$ \\
\hline$I_{c}$ & $-2.610 \angle-157.2^{\circ}$ & $2.6095 \angle 22.8177^{\circ}$ \\
\hline$V_{a}$ & $0.461 \angle-42.6^{\circ}$ & $0.4610 \angle-42.6462^{\circ}$ \\
\hline$V_{b}$ & $0.465 \angle 179.3^{\circ}$ & $0.4651 \angle 179.3410^{\circ}$ \\
\hline$V_{c}$ & $0.465 \angle 179.3^{\circ}$ & $0.4651 \angle 179.3410^{\circ}$ \\
\hline
\end{tabular}

\section{Procedure to the calculation of two-simultaneous fault}

In this particular item, we will give two numerical examples to illustrate the calculation of simultaneous SLG-BLL-F step-by-step. The first example is a small system and the second example is a medium system. Thus, we will take as examples, the modified Example 9.1 of the reference [3] and the IEEE 14-bus test system [17].

In general, the fault analysis is performed from the following path [4]:

1. The power system must be represented by its positive, negative and zero-sequence networks (when faults without earth occur the zero-sequence network is not used, and the negative and zero-sequence networks are removed for the balanced threephase fault condition). Then, the calculation of impedances in pu for all power systems components is required: lines, transformers, generators, cables and other elements of the power system.

2. In this step, each of the sequence networks should be reduced to its simplest form. The three sequence networks equivalent, i.e. positive, negative and zero are represented as series-parallel and a series arrangement of the p.u. impedances. Then, these are substituted by the single equivalent impedance for each sequence network. When this procedure is performed delta-star or star-delta transformations may be necessary.

3. The suitable symmetrical-component equations are used to find the phase-sequence components of the current in fault under the particular short-circuit condition.

4. The p.u. phase-current values at the point of fault are determined.

5. Finally, the actual values of the phase-currents are calculated by multiplying obtained p.u. values by the base current at the point of fault.

The procedure described above provides a complete analysis of the given power system for specified fault condition. This procedure can be applied for two types of case studies: First case study is using small systems and second case study is using medium or large systems. The two case studies are showed as follows:

First case study of fault analysis: small systems

Consider the modified Example 9.1 of the reference [3].

The single-line diagram of a three-phase power system is shown in Fig. 3. Equipment ratings are given as follows:

Synchronous generator:

G1 1000 MVA $15 \mathrm{kV} X_{d}^{\prime \prime}=X_{2}=0.18, X_{0}=0.07$ per unit

G2 1000 MVA $15 \mathrm{kV} X_{d}^{\prime \prime}=X_{2}=0.20, X_{0}=0.10$ per unit

G3 500 MVA $13.8 \mathrm{kV} X_{d}^{\prime \prime}=X_{2}=0.15, X_{0}=0.05$ per unit

G4 750 MVA $13.8 \mathrm{kV} X_{d}^{\prime \prime}=X_{2}=0.40, \quad X_{0}=0.10$ per unit

Transformers:

T1 1000 MVA $15 \mathrm{kV} \Delta / 765 \mathrm{kV} Y X=0.10$ per unit

T2 1000 MVA $15 \mathrm{kV} \Delta / 765 \mathrm{kV} Y X=0.10$ per unit

T3 1000 MVA $15 \mathrm{kV} \Delta / 765 \mathrm{kV} Y X=0.12$ per unit

T4 1000 MVA $15 \mathrm{kV} \Delta / 765 \mathrm{kV} Y X=0.11$ per unit

Transmission Lines:

$1-2765 \mathrm{kV} X_{1}=50 \Omega, \quad X_{0}=150 \Omega$

$1-3765 \mathrm{kV} X_{1}=40 \Omega, \quad X_{0}=100 \Omega$

$2-3765 \mathrm{kV} X_{1}=40 \Omega, \quad X_{0}=100 \Omega$

The inductor connected to Generator 3 neutral has a reactance of 0.05 per unit using generator 3 ratings as a base. Calculate simultaneous SLG-BLL-F at bus 1 with a SLGI of zero ohms. Prefault load currents and $\Delta-Y$ transformer phase shifts are neglected. Prefault voltage is 1.0 per unit.

\section{Solution}

First step: The first step is to choose apparent power base. The power base can be adopted equal to the power rating of any power system transformer or generator, or may be chosen as a whole number as 1000 or 100 MVA. Here, apparent power base is chosen as a $1000-M V A$ base in the zone of line 1-2.

Second step: The second step is to choose voltage base. The choice of the voltage base is determined by the voltage rating of

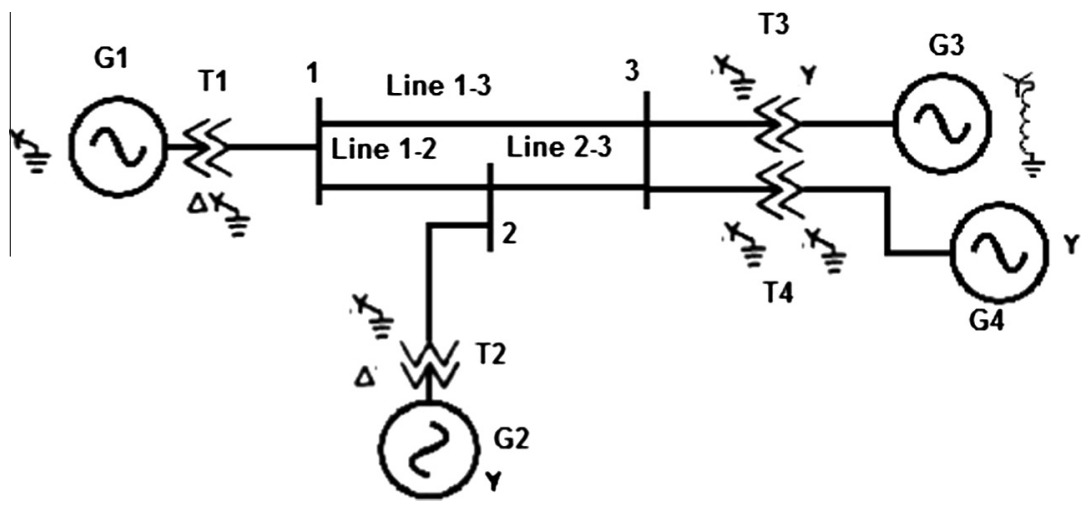

Fig. 3. Power system for numerical example. 
the bus where the fault is located. Here, voltage base is chosen as $765 \mathrm{kV}$.

Third step: In this step the current base is calculated.

$I_{\text {base }}=\frac{S_{\text {base }}}{\sqrt{3} V_{\text {base }}}=\frac{1000}{765 \sqrt{3}}=0.755 \mathrm{kA}$

Fourth step: In this step all per unit reactances are calculated. Synchronous generator:

$G 1 X_{1}=X_{d}^{\prime \prime}=X_{2}=0.18, \quad X_{0}=0.07 \mathrm{pu}$

$G 2 X_{1}=X_{d}^{\prime \prime}=X_{2}=0.20, \quad X_{0}=0.07 \mathrm{pu}$

$G 3 X_{1}=X_{2}=X_{d}^{\prime \prime}=0.15\left(\frac{13.8}{15}\right)^{2}\left(\frac{1000}{500}\right)=0.2539 \mathrm{pu}$

$X_{0}=0.05\left(\frac{13.8}{15}\right)^{2}\left(\frac{1000}{500}\right)=0.08464 \mathrm{pu}$

$3 X_{n}=3 X_{0}=0.2539 \mathrm{pu}$

$G 4 X_{1}=X_{2}=X_{d}^{\prime \prime}=0.40\left(\frac{13.8}{15}\right)^{2}\left(\frac{1000}{750}\right)=0.4514 \mathrm{pu}$

$X_{0}=0.10\left(\frac{13.8}{15}\right)^{2}\left(\frac{1000}{500}\right)=0.1129 \mathrm{pu}$

Transformers:

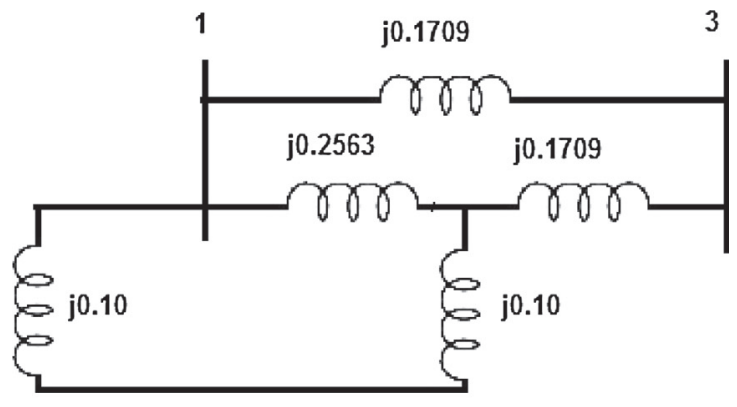

(a) Zero sequence circuit

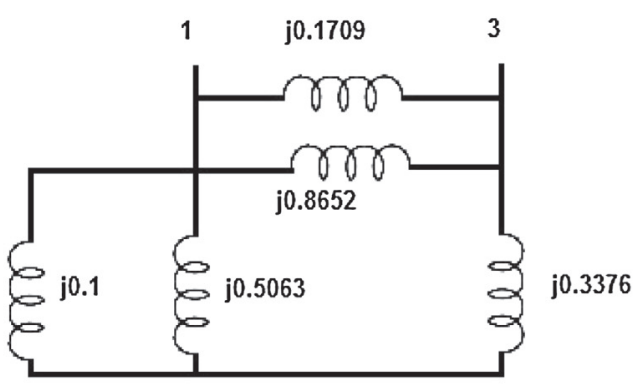

(b) Reduction 1

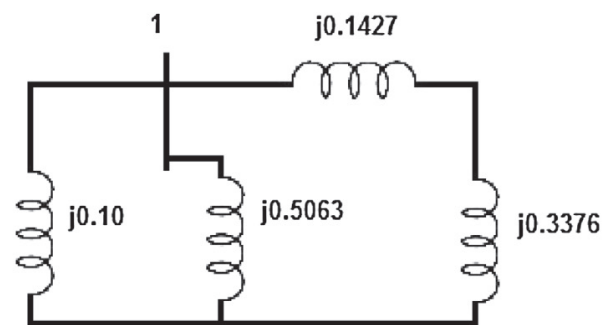

(c) Reduction 2

Fig. 4. (a-c) Zero sequence circuit and reductions.
$X_{T 1}=0.10 \mathrm{pu}$

$X_{T 2}=0.10 \mathrm{pu}$

$X_{T 3}=0.12\left(\frac{1000}{500}\right)=0.24 \mathrm{pu}$

$X_{T 4}=0.11\left(\frac{1000}{750}\right)=0.1467 \mathrm{pu}$

Transmission Lines:

$Z_{\text {BASE-H }}=\frac{(765)^{2}}{1000}=585.23 \Omega$

Positive/negative sequence

$X_{12}=\frac{50}{585.23}=0.08544 \mathrm{pu}$

$X_{13}=X_{23}=\frac{40}{585.23}=0.06835 \mathrm{pu}$

Zero sequence

$X_{12}=\frac{150}{585.23}=0.2563 \mathrm{pu}$

$X_{13}=X_{23}=\frac{100}{585.23}=0.1709 \mathrm{pu}$

Fifth step: In the fifth step each of the sequence networks should be reduced to its simplest form.

Zero sequence Thevenin equivalent and their reductions are showed in Fig. 4(a)-(c).

The diagram of the Fig. 4 (b) is obtained using $\Delta-Y$ conversion. According to Fig. 4(c) we obtain:

$X_{0}=0.10 / / 0.5063 / /(0.1427+0.3376)$

$X_{0}=0.071114 \mathrm{pu}$

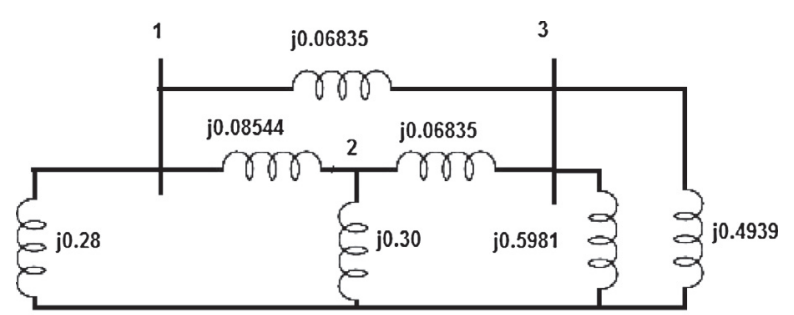

(a) Negative sequence circuit

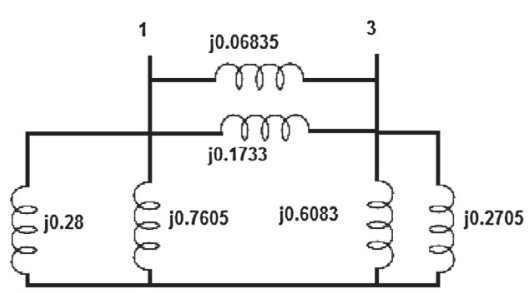

(b) Reduction 1

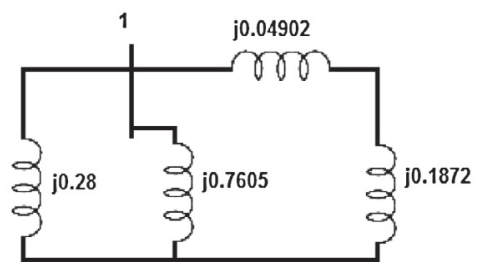

(c) Reduction 2

Fig. 5. (a-c) Negative sequence circuit and reductions. 


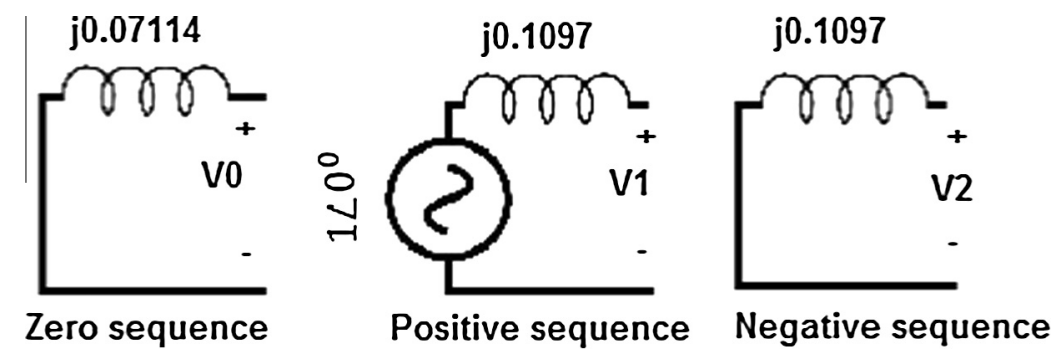

Fig. 6. Equivalent zero, positive and negative sequence networks.

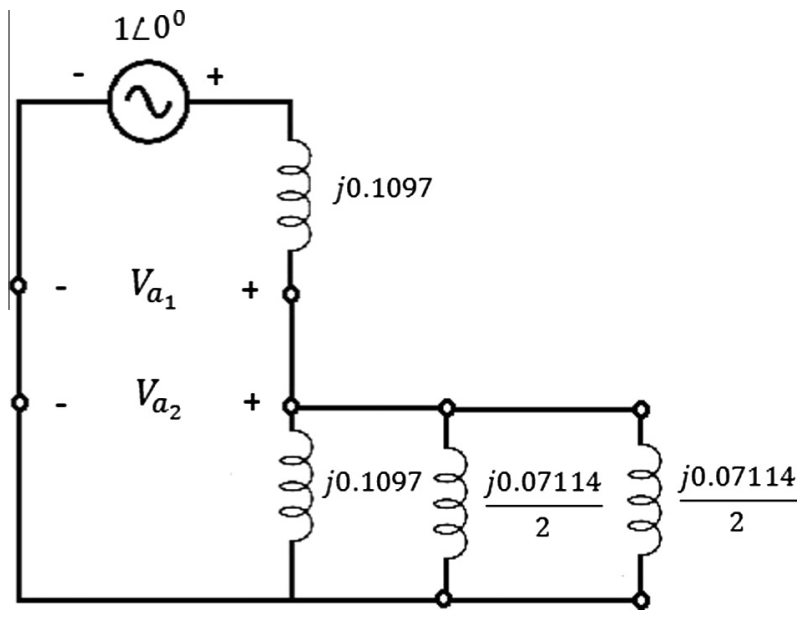

Fig. 7. Equivalent circuit diagram to simultaneous SLG-BLL-F.

where // is a parallel impedance.

Negative sequence Thevenin equivalent and their reductions are showed in Fig. 5(a)-(c).

The diagram of the Fig. 4(b) is obtained using $Y-\Delta$ conversion. According to Fig. 5(c) we obtain:

$X_{2}=0.28 / / 0.7605 / /(0.04902+0.1872)$

$X_{2}=0.1097 \mathrm{pu}$

Similarly,

$X_{1}=0.1097 \mathrm{pu}$

Sixth step: The equivalent positive, negative and zero-sequence networks are represented as an equivalent circuit diagram.

In this step, Thevenin equivalents as viewed from bus 1. Fig. 6 shows these equivalent circuits.

Seventh step: Equivalent circuit diagram in the 012-system to simultaneous SLG-BLL-F.

Fig. 7 shows the combination of the equivalent zero, positive and negative sequence networks to calculate simultaneous SLGBLL-F.

The currents and voltages of the system of symmetrical components are calculated using Eqs. (5a) and (5b) or using the circuit of the Fig. 7.

$I_{a_{1}}=7.9998 \angle-90^{\circ} \mathrm{pu}$

$I_{a_{2}}=1.1160 \angle 90^{\circ} \mathrm{pu}$

$I_{a_{0}}=3.4419 \angle-90^{\circ} \mathrm{pu}$

$V_{a_{1}}=0.1224 \angle 180^{\circ} \mathrm{pu}$

$V_{a_{2}}=0.1224 \angle 0^{\circ} \mathrm{pu}$

$V_{a_{0}}=0.2449 \angle 0^{\circ} \mathrm{pu}$
Eighth step: The p.u. phase-current values at the point of fault are determined.

Using Eq. (2)

$$
\left[\begin{array}{l}
I_{a} \\
I_{b} \\
I_{c}
\end{array}\right]=\left[\begin{array}{ccc}
1 & 1 & 1 \\
1 & \vec{a}^{2} & \vec{a} \\
1 & \vec{a} & \vec{a}^{2}
\end{array}\right]\left[\begin{array}{c}
3.4419 \angle-90^{\circ} \\
7.9998 \angle-90^{\circ} \\
1.1160 \angle-90^{\circ}
\end{array}\right]
$$

Therefore:

$I_{a}=10.3256 \angle-90^{\circ} \mathrm{pu}$

$I_{b}=7.8945 \angle-180^{\circ} \mathrm{pu}$

$I_{c}=7.8945 \angle 0^{\circ} \mathrm{pu}$

Ninth step: The actual values of the phase-currents are calculated. Using $I_{\text {base }}$ calculated in third step

$$
\begin{aligned}
& I_{a}=7.7958 \angle-90^{\circ} \mathrm{kA} \\
& I_{b}=5.9603 \angle-180^{\circ} \mathrm{kA} \\
& I_{c}=5.9603 \angle 0^{\circ} \mathrm{kA}
\end{aligned}
$$

Now, we can make a comparison with the classical fault situations. The results are shown in Table 2.

One understands then that a simultaneous SLG-BLL-F may have a current value at a phase higher than the current value of the three-phase fault. The results of the simultaneous SLG-BLL-F include the results of LG and LL faults.

Fig. 8(a) and (b) present the fault currents at buses 2 and 3. It is worth noting that results of the simultaneous SLG-BLL-F also include the results of LG and LL faults.

Then, the equivalent circuit developed can substitute both the equivalent circuits used to calculate a single line-to-ground fault and a bolted line-to-line fault.

Second case study of fault analysis: medium and large systems

The IEEE 14-bus test system [17] was also used for testing the approach described. However, the fault analysis for large systems is done similarly.

The single-line diagram of the IEEE 14-bus is shown in Fig. 9.

At this time, the procedure of the Fifth step, i.e. (in the fifth step each of the sequence networks should be reduced to its simplest form), is done using classical techniques to form impedance matrices. The short-circuit matrix is formed using classical procedure by a step-by-step formation [18]. Other steps are the same as in the case study of the small system.

The buses selected for the location of the faults were: 1 and 12 , because they present, respectively, the highest and lowest threephase short-circuit power. The Thevenin equivalent impedances (pu) calculated are: Bus 1, $Z_{1}=0.009118+0.079893 j ; Z_{0}=$ $0.377863+0.173159 j ; \quad$ Bus $12, \quad Z_{1}=0.129671+0.299170 j$; $Z_{\mathrm{o}}=0.459552+0.308492 j$. 
Table 2

Fault current results - bus 1

\begin{tabular}{llll}
\hline Fault & \multicolumn{2}{l}{ Currents (kA) } & $I_{b}$ \\
\cline { 2 - 4 } bus 1 & $I_{a}$ & $-6.883 \angle-30^{\circ}$ & $I_{c}$ \\
\hline Three phase (LLL) & $6.883 \angle-90^{\circ}$ & $-7.465 \angle-37^{\circ}$ & $-6.883 \angle-150^{\circ}$ \\
Line-to-line-to-ground (LLG) & 0 & $5.960 \angle-180^{\circ}$ & $-7.465 \angle-143^{\circ}$ \\
Line-to-line (LL) & 0 & 0 & $5.960 \angle 0^{\circ}$ \\
Single line-to-ground (LG) & $7.796 \angle-90^{\circ}$ & $5.960 \angle-180^{\circ}$ & 0 \\
SLG-BLL-F & $7.796 \angle-90^{\circ}$ & $5.960 \angle 0^{\circ}$ \\
\hline
\end{tabular}
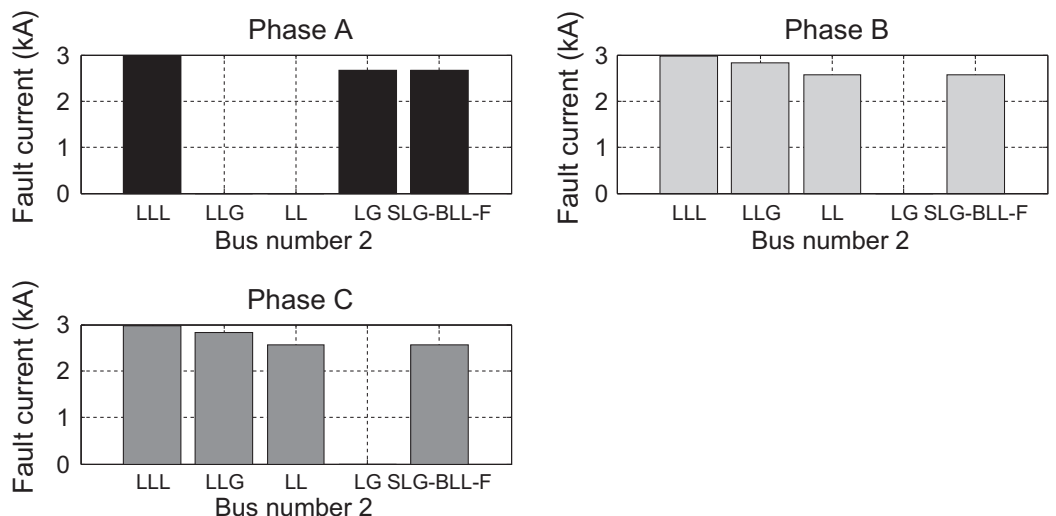

(a) - Bus 2
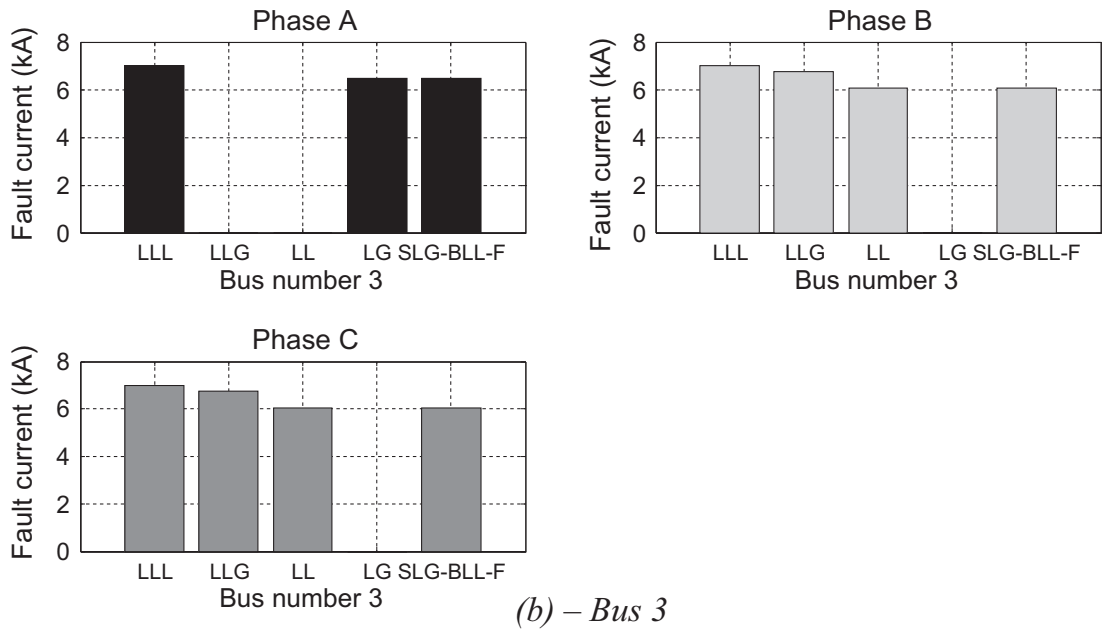

Fig. 8. (a, b) Fault currents - buses: 2 and 3.

Fig. 10 shows the simultaneous SLG-BLL-F currents of the buses 1 and 12 calculated through Eqs. (5a) and (2), and single-line-toground fault currents and line-to-line fault currents of the buses 1 and 12 calculated using ANAFAS. The values confirm that the equivalent circuit developed can substitute both the equivalent circuits used to calculate a single line-to-ground fault and a bolted line-to-line fault.

According to the simulation results the advantages and disadvantage of the new equivalent circuit are: (a) Advantages - It can be used for calculating a combination of simultaneous faults in the same location in small and large power systems, and it can substitute equivalent circuits which are used to calculate a single line-to-ground fault and a bolted line-to-line fault; (b) Disadvantage - The impedance between the two phases of the line - line fault is not included in the equivalent circuit.

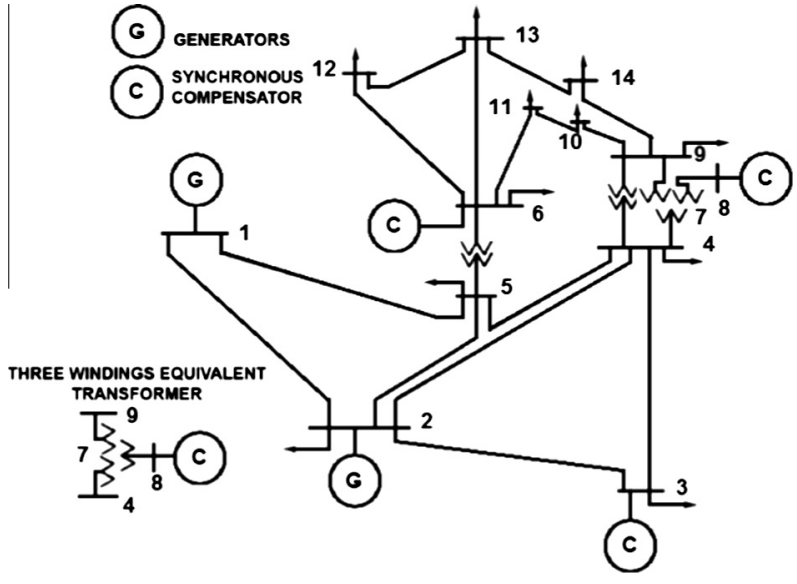

Fig. 9. Topology of the IEEE 14-bus test system. 


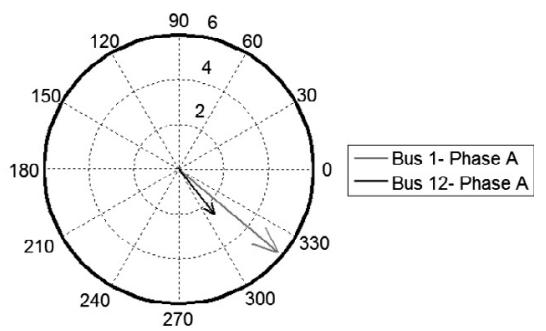

(a) ANAFAS-Single-line-to-ground fault currents (pu) - Buses: 1 and 12

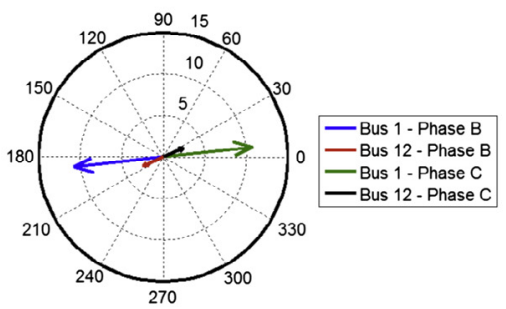

(b) ANAFAS-Line-to-line fault currents (pu) - Buses: 1 and 12

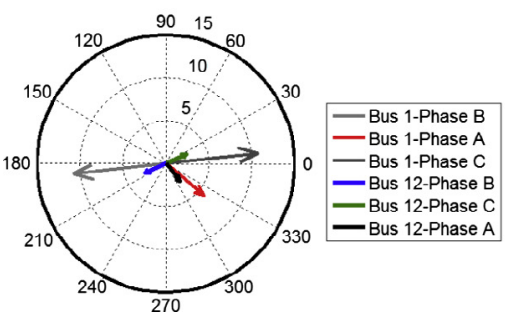

(c) Equivalent circuit-Simultaneous SLG-BLL-Fcurrents (pu) - Buses: 1 and 12

Fig. 10. $(a-c)$ Fault currents of the IEEE 14-bus system.

\section{Conclusion}

This paper describes an approach based on symmetrical components theory to calculate short-circuit currents that result from a simultaneous SLG-BLL-F. Moreover, numerical results were compared with results of the commercial software ANAFAS and the new equivalent circuit was validated. The advantages of the new equivalent circuit developed are described as follows. It can substitute equivalent circuits which are used to calculate a single line-toground fault and a bolted line-to-line fault, and it can be used for calculating a combination of simultaneous faults in the same location in small and large power systems. In conclusion, we suggest that this new equivalent circuit should be incorporated in shortcircuit analysis literature.

\section{References}

[1] Anderson Paul M. Analysis of faulted power systems. New York: IEEE Press Power Systems Engineering Series; 1995.

[2] Betanzos Manuel J, Lemus Zavala HE, Alcazar Ramirez E, Escobedo DS, Altuve HJ. Protecting distribution feeders for simultaneous faults. In: 63rd annual conference for protective relay engineers. IEEE conference publications; 2010. p. 1-9.

[3] Duncan Glover J, Sarma Mulukutla S, Overbye Thomas J. Power system analysis \& designs. fifth ed. USA: Cengage Learning; 2011.

[4] Grainger JJ, Stevenson Jr WD. Power system analysis. New York: McGraw-Hill, Inc.; 1994.

[5] Blackburn JL. Symmetrical components for power systems engineering. New York: Dekker; 1993.

[6] Wang Yuanyuan, Zeng Xiangjun, Dong Zhaoyang, Huang Yue. Novel protection scheme of stator single-phase-to-ground fault for power transformers. Int J Electr Power Energy Syst 2013;53:321-8
[7] Rongjie Wang, Yiju Zhan, Haifeng Zhou, Bowen Cui. A fault diagnosis method for three-phase rectifiers. Int J Electr Power Energy Syst 2013;52:266-9.

[8] Ou Ting-Chia. Ground fault current analysis with a direct building algorithm for microgrid distribution. Int J Electr Power Energy Syst 2013;53: $867-75$.

[9] Vyas Bhargav Y, Maheshwari RP, Das Biswarup. Improved fault analysis technique for protection of thyristor controlled series compensated transmission line. Int J Electr Power Energy Syst 2014;55:321-30.

[10] Filipovic'-Grcic' Dalibor, Filipovic'-Grcic' Bozidar, Capuder Kosjenka. Modeling of three-phase autotransformer for short-circuit studies. Int J Electr Power Energy Syst 2014;56:228-34.

[11] Tardón C, López E, Tardón J, Lópezc M, Poloujadoffd M, Lefranc G. Optimal stochastic fault tracking for rural electrical distribution networks via emergency brigades. Electric Power Syst Res 2013;101:56-62.

[12] Zhang J, He ZY, Lin S, Zhang YB, Qian QQ. An ANFIS-based fault classification approach in power distribution system. Int J Electr Power Energy Syst 2013;49:243-52.

[13] Hooshyar Hossein, Baran Mesut E. Fault analysis on distribution feeders with high penetration of PV systems. IEEE Trans Power Syst 2013;28: 2890-6.

[14] Meléndez Joaquim, Quiroga Oscar, Herraiz Sergio. Analysis of sequences of events for the characterisation of faults in power systems. Electric Power Syst Res 2012;87:22-30.

[15] Pothisarn C, Ngaopitakkul A. Analysis of characteristics using wavelet transform for simultaneous faults in electrical power system. in: Third international conference on innovations in bio-inspired computing and applications (IBICA); 2012. p. 93-7.

[16] Moura AP, Lopes JAP, de Moura Adriano AF, Sumaili J, Moreira CL. IMICV fault analysis method with multiple PV grid-connected inverters for distribution systems. Electr Power Syst Res 2015;119:119-25.

[17] Toledo Olga Moraes, Filho Delly Oliveira, Diniz Antonia Sonia Alves Cardoso, Martins Jose Helvecio, Vale Maria Helena Murta. Methodology for evaluation of grid-tie connection of distributed energy resources-Case study with photovoltaic and energy storage. IEEE Trans Power Syst 2013;28:1132-9.

[18] Moura AP, Moura Adriano AF, Moura André AF. Analysis of injected apparent power and flicker in a distribution network after wind power plant connection. IET Renew Power Gener 2008;2:113-22. 